\title{
Classification of Eog Signal using Elman Recurrent Neural Network for Different Age Groups
}

\author{
S. Ramkumar, J. MacklinAbraham Navamani, K. Sathesh Kumar, V. Vasanthi, G. Emayavaramban, \\ P. Sriramakrishnan, M. Illayaraja,
}

\begin{abstract}
Disabled people in the world population were increasing constantly, So need of rehabilitative system also increasing every day. To overcome such wretched condition, we can use the biosignal techniques to device the rehabilitative devices. Rehabilitative devices may be called as Brain Computer Interface (BCI) or Human Computer Interface (HCI). We studied the performances of ten male subjects between the age group of 18 to 25 using mean features and Elman Recurrent Neural Network (ERNN). We conducted our study with two different age group from 18 to 21 and 22 to 25 . The average classification accuracy of $91.00 \%, 93.57 \%$ were attained for the age group of 18 to 21 and 22 to 25. From the individual analysis we identified that performances from the age group 22 to 25 were appreciated then that of the age group from 18 to 21 . In between the study we analyzed that subject $s$ from the age group 22 to 25 performed all the following five tasks neatly and accurately without any deviation and disturbance compared with age group from 18 to 21 . Finally from the obtained result we concluded that subject from the age group 22 to 25 was higher than that of age group from 18 to 21 .
\end{abstract}

Keywords : Locked in State, Mean, Spinal Cord Injury, Brain Computer Interface, Human Computer Interface, Elman Recurrent Neural Network.

\section{INTRODUCTION}

First Spinal Cord Injury (SCI) was caused in vertebral column or backbone column extending from neck to tail which was responsible for transmitting the body weight in standing and walking. The people affected with Spinal Cord Injury (SCI) were unable to communicate the messages from

Revised Manuscript Received on December 16, 2019

* Correspondence Author

S.Ramkumar*, School of Computing, Kalasalingam Academy of Research and Education, Krishnankoil, Tamilnadu, India. Email: ramkumar.drl2013@gmail.com

J. MacklinAbraham Navamani, Department of Computer Applications, Karunya Institute of Technology and Sciences, Coimbatore, India. Email: macklin@karunya.edu

K. Sathesh Kumar, School of Computing, Kalasalingam Academy of Research and Education, Krishnankoil, Tamilnadu, India. Email: sathesh.drl@gmail.com

V.Vasanthi, Department of IT \& BCA, Adithya College of Arts and Science, Coimbatore, India. Email: vasanthiv@ skacas.ac.in

G. Emayavaramban, Department of Electric and Electronic Engineering, Karpagam Academy of Higher Education, Coimbatore, India. Email: emayavaramban.g@kahedu.edu.in

P.Sriramakrishnan, School of Computing, Kalasalingam Academy of Research and Education, Krishnankoil, India. Email: sriram0210@gmail.com

M.Illayaraja,, School of Computing, Kalasalingam Academy of Research and Education, Krishnankoil, Tamilnadu, India. Email: ilayaraja.m@klu.ac.in the brain. So the affected areas were unable to perform motor, control sensory, muscle voluntary actions and make the muscles inactive below the level of injury [1]-[2]. There are two types of Spinal Cord Injuries they are

1. Tetraplegia or quadriplegia $\rightarrow$ Spinal cord affected near to the neck area is called Tetraplegia or quadriplegia. It causes loss of muscles activities in both hands and legs.

2. Paraplegia $\rightarrow$ Spinal cord affected near to the thoracic or lumbar areas are called Paraplegia. It causes muscles activities in legs and lower part of the body.

Several devices have been developed for persons with Motor Neuron Disease (MND) using bio signals to overcome the Locked in State (LIS). Some of the well known rehabilitative devices were listed here they are Eye Writing System [3], Game Controller [4], Home Appliances [5], Virtual Keyboard [6]-[7], Intelligent Car Driving Controller[8], Joystick Controller [9] and Vowel Recognition System [10]. So we planned to make preliminary study to develop communication device using rehabilitative device. Rehabilitative devices replaced the communication channels in the lack of biological channels. Initially we start our experiment with five tasks to perform five state device using five movements to ensure the potential of developing control signals to control the external device using classification techniques.

\section{BACKGROUND STUDY}

Locked in State (LIS) affected individuals were growing rapidly, So there is a need of assistive devices and its technologies to beat such problem. Some of the important studies related to this researcher were listed below. Ramkumar, et.al (2019) designed the HCI using Neural Network and Power Spectral Density from ten subjects and obtained $91.38 \%$ for all the right handed subjects and $93.38 \%$ for all left hand subjects [11]. Qiyun Huang, et. al (2019) modeled robotic arm for spinal cord injury persons using blink detection algorithm and obtained the accuracy of $99.3 \%$ and $97.3 \%$ [12]. S.Fang, et. al (2019) created a rehabilitative device for ALS affected persons from ten subjects using neural network with periodogram features and obtained the maximum accuracy of $93.67 \%$ and $92.28 \%$ for male and female subjects[13]. Y.Li, et. al (2018) designed EOG based wheelchair control and tested with normal and spinal cord injured persons using blink detection algorithm with steady-state visual evoked potentials (SSVEPs) and gained the accuracy of $96.7 \%$ and $91.7 \%$ [14]. 


\section{Classification of Eog Signal using Elman Recurrent Neural Network For Different Age Groups}

Gu Jialu, et. al (2018) designed EOG controlled wheelchair from twenty subjects Layered recurrent neural network (LRNN) model with convolution and Plancherel features and obtained the accuracy of $90.72 \%$ and $91.28 \%$ respectively[15].

S.He and Y.Li,(2017) modeled EOG based Speller from wave detection algorithm and support vector machine techniques from eight healthy subjects and obtained the accuracy of $93.43 \%$ and $94.4 \%$ [16]. K.R.Lee, et. al (2017) developed eye writing system from twenty subjects using vertical and horizontal eye movement tasks and obtained an average accuracy of $87.38 \%$ for twenty nine symbolic patterns respectively [17]. N.Barbara and T.A.Camilleri, et. al (2016) designed EOG glass based Speller using wet electrodes by implementing threshold algorithm and obtained the accuracy of $90.59 \%$ [18]. A.Rakshit, et. al (2016) designed digit recognition system for speech disabled patients using twelve healthy subjects by applying the Power spectral density feature with support vector machine to categorize the different tasks and obtained the accuracy of $90 \%$ [19]. From the latest survey we confirmed that EOG based HCI was possible in the real time environment to direct the external devices. So we planned to conduct preliminary study to discover the acquired movement to activate the external devices by means of two different age group subject $\mathrm{s}$ from 18 to 21 and $22-25$ using five tasks.

\section{METHODOLOGY OF THE RESEARCH}

\section{A. Experimental Setup}

Two points were on the wall with a distance of one meter. Subject was placed one meter away from the two marked points. The room was not covered with any sound proof materials and lighted with tube lights. Initially the subjects were requested to perform the five movements prior to collecting the signals. All the subjects participated in the events were trained for five minutes before acquiring the signals.

\section{B. Data Collection}

All the subjects were requested to perform the five tasks individually in one session as per protocol followed in our prior study [20]-[22]. Each task was recorded for ten times and each trial was recorded for two seconds. Totally two hundred samples were acquired for one trial. Fifty trials were recorded for five tasks per subjects. Totally master dataset of 500 samples were used to extract the features to analyze the individual task.

\section{Feature Extraction}

Feature extraction is a technique of removing the irrelevant data and extracting the most prominent features from the original dataset to encourage the classification accuracy. In this study we applied the mean method to extract the features. Mean is otherwise called arithmetic average which states that number of input values divided by the total number of sample items [23]-[25] which was shown in the equation.1

$$
\bar{M}=\left(\Sigma X_{\mathrm{i}}\right) / \mathrm{N}
$$

$\bar{M}$ represents Sample Mean

$\varepsilon$ Indicates the summation (add up)

$X_{\mathrm{i}}$ Number of current Input value

$\mathrm{N}$ Total number of sample item

From the feature extraction method sixteen samples from each trial was given as an input. Follow the same procedure for fifty trials for the following five tasks per subjects to classify the data.

\section{NETWORK MODEL}

For performing classification we used Elman Recurrent Neural Network (ERNN) with sixteen input features and four output neurons. During 1990 ERNN was developed by Jeffrey L.Elman. It was two layered back propagation network with the accumulation of feedback connection from the output of the hidden layer to its input. There was a feedback connection from the first layer output to the first layer input, a recurrent connection was entrenched, which grant the Elman network to sense and generate time varying patterns. The feedback tracks allow an Elman network to learn to distinguish and generate temporal as well as spatial patterns. The weights on the feedback connection to the context units are fixed, and information processing is sequential in time, therefore training in this network is more difficult than for a standard back propagation network. The delay in this connection stores values from the previous time step, which can be used in the current time step. Here a specific group of units called context units receives feedback signals from the previous time step. The weights from the context units to the hidden units were trained in exactly the same manner as the weights from the input units to the hidden units. At the time the activation of the context units imply the activations of the hidden units at previous time step. This improves the classification rate and training time of the network in comparison to a feed forward neural network. The hidden neuron was fixed as eight using trial and error method. The maximum number of training will stop after 1000 iteration and the error tolerance rate was fixed at 0.1 [26]-[37]. The architecture implemented in this study was represented in the fig. 1 .

\section{EXPERIMENTAL RESEARCH}

In this study we mainly focused to develop the five states HCI using five tasks collected from ten subjects. Master Dataset was created by executing five tasks from ten subjects. Age group was in between 18 to 25 . During the data collection we divide the subjects in to two levels (Age group of 18 to 21 and Age group of 22 to 25 ) to analyze the performances of the different subjects individually by using Mean features with ERNN model. From the Table.1 and Table. 2 we identified that network model using Mean features showed the maximum performances for the age group of 22-25 then that of the subjects with age group of 18-21. The maximum and minimum performances of the two age groups were illustrated in the fig. 2 to fig.5. From the Table.1 and Table. 2 we interpret that maximum performances of $94.32 \%$ and $95.68 \%$ were obtained for the subjects S3 and S10 from two different age groups. From the same Tables we obtained the minimum performances of $88.19 \%, 89.13 \%$ for subjects S5 and S6 which was shown in the fig. 2 to fig. 5 respectively. The average classification accuracy of $91.00 \%, 93.57 \%$ were attained for age group of 18 to 21 and 22 to 25 . Individual highest and lowest classification accuracy of $92.44 \%, 91.70 \%$ for age group of 18 to 21 and $94.32 \%, 93.12 \%$ for age group of 22 to 25 for the subjects S3, S4 and S10, S8 were obtained which was illustrated in the fig.6. Finally from the analyzed result we concluded that subject from the age group 22 to 25 performances were higher than that of age group from 18 to 21. 


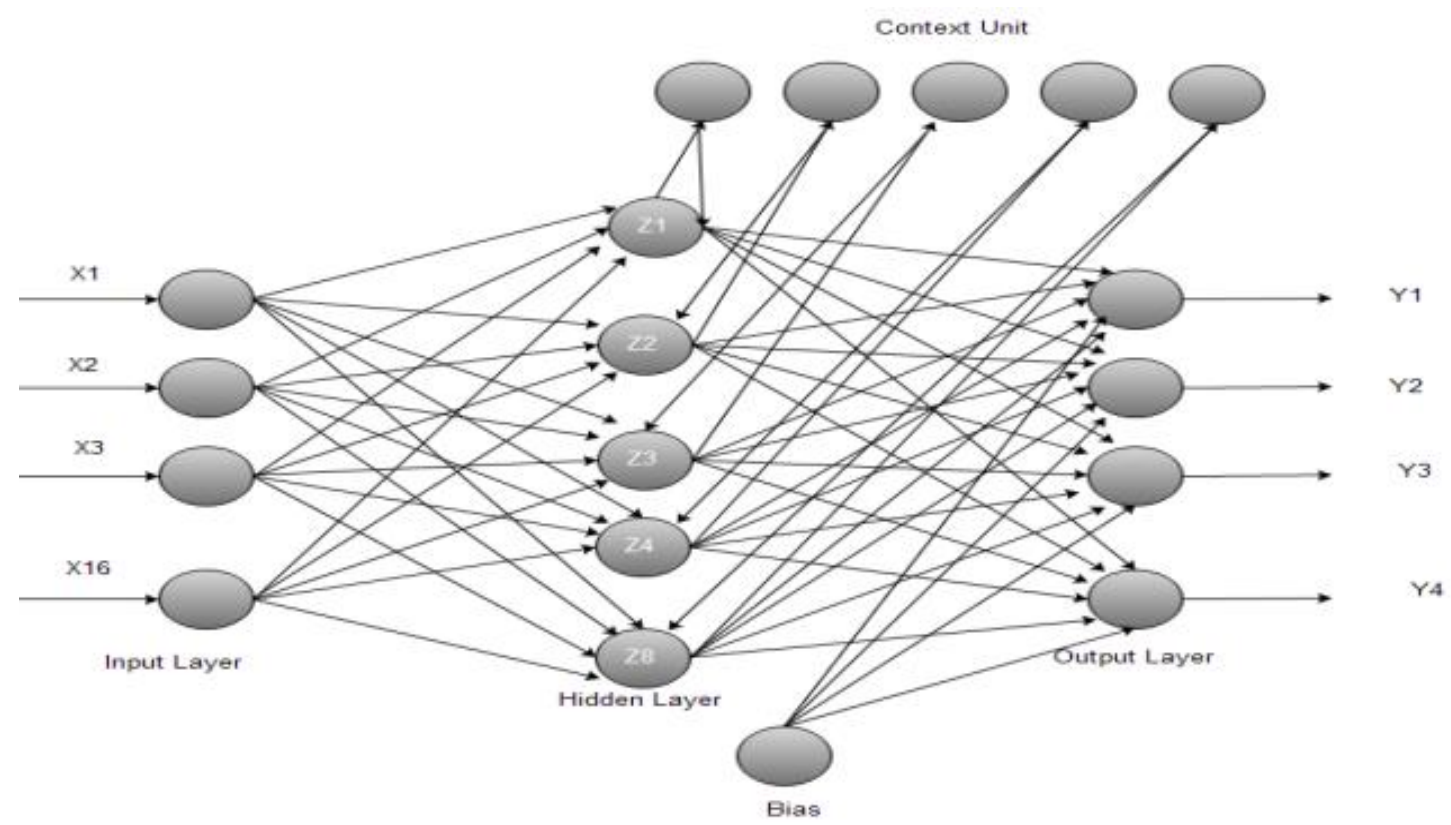

Fig.1. ERNN Architecture Implemented in this Study

Table I. Classification accuracy using Mean features and ERNN model for the age group 18 to 21

\begin{tabular}{|c|c|l|l|l|l|l|}
\hline \multirow{2}{*}{ Subjects } & \multirow{2}{*}{$\begin{array}{l}\text { Mean } \\
\text { Training } \\
\text { Time (sec) }\end{array}$} & \multirow{2}{*}{$\begin{array}{l}\text { Mean } \\
\text { Testing } \\
\text { Time (sec) }\end{array}$} & \multicolumn{4}{|l|}{ Average Performance (\%) } \\
\cline { 4 - 7 } & & & MAX & MIN & MEAN \\
\hline S1 & 13.45 & 0.51 & 1.71 & 93.28 & 88.48 & 92.11 \\
\hline S2 & 13.76 & 0.54 & 1.78 & 93.90 & 88.42 & 91.86 \\
\hline S3 & $\mathbf{1 4 . 0 1}$ & $\mathbf{0 . 5 2}$ & $\mathbf{1 . 8 2}$ & $\mathbf{9 4 . 3 2}$ & $\mathbf{8 8 . 7 6}$ & $\mathbf{9 2 . 4 4}$ \\
\hline S4 & 13.55 & 0.56 & 1.81 & 93.65 & 89.24 & 91.70 \\
\hline S5 & 13.89 & 0.57 & 1.77 & 93.85 & 88.19 & 91.88 \\
\hline
\end{tabular}

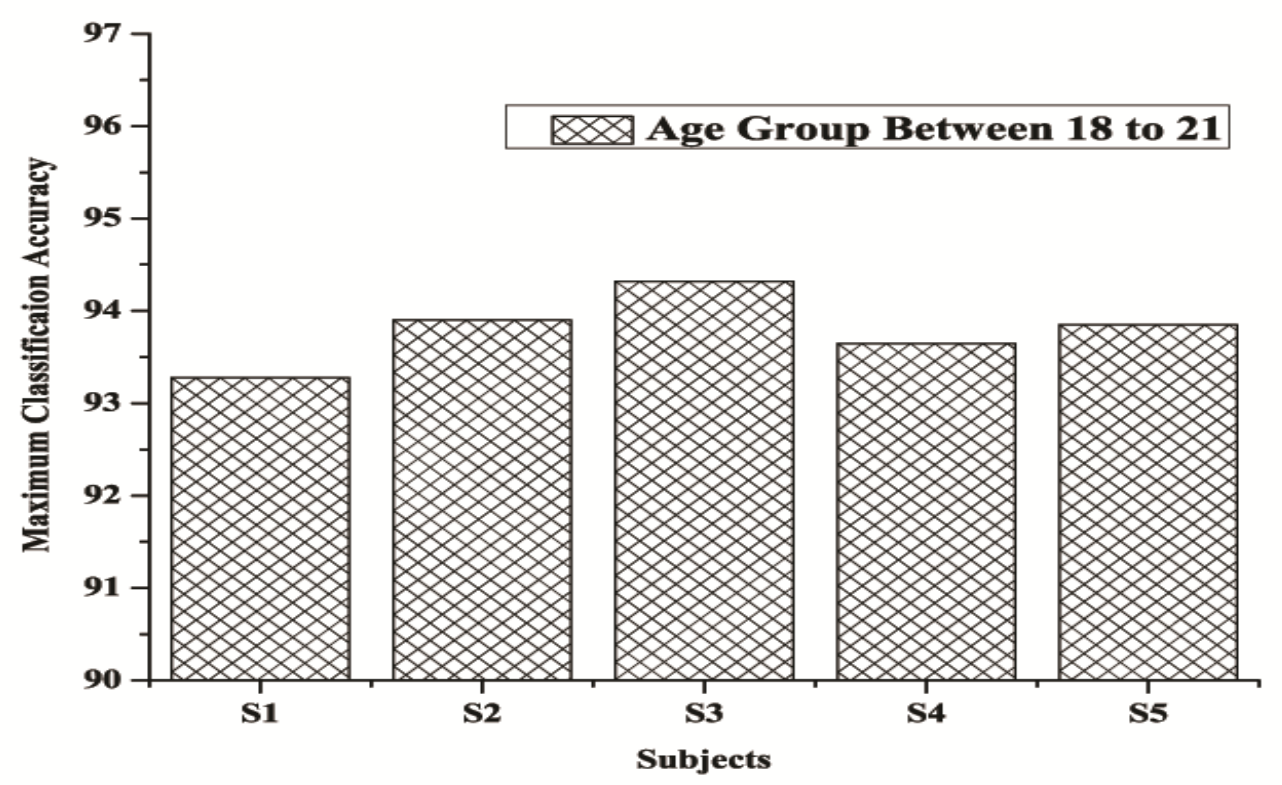

Fig.2. Maximum accuracy of five subjects for the age group between 18 to 21 


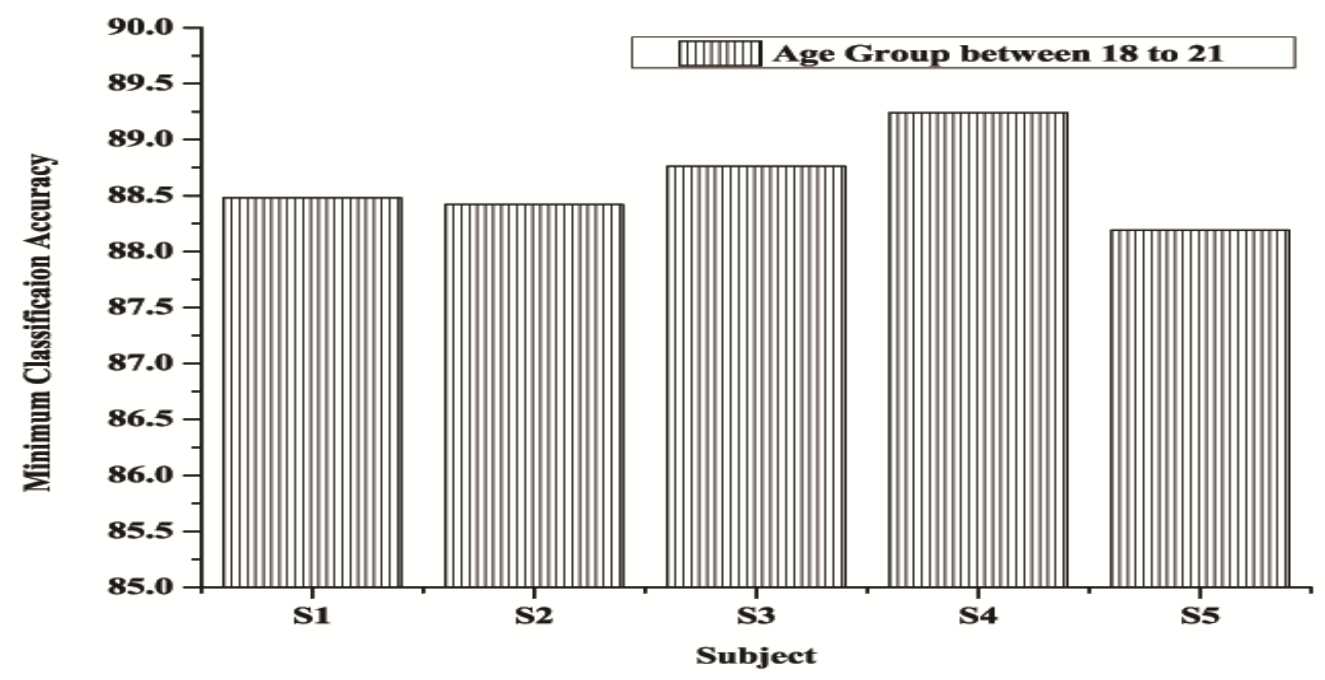

Fig..3. Minimum accuracy of five subjects for the age group between 18 to 21

Table II. Classification accuracy using Mean features and ERNN model for the age group 22 to 25

\begin{tabular}{|c|c|c|c|c|c|c|}
\hline \multirow{2}{*}{ Subjects } & \multirow{2}{*}{$\begin{array}{l}\text { Mean } \\
\text { Training } \\
\text { Time } \\
\text { (sec) }\end{array}$} & \multirow{2}{*}{$\begin{array}{l}\text { Mean } \\
\text { Testing } \\
\text { Time } \\
\text { (sec) }\end{array}$} & \multicolumn{4}{|c|}{ Average Performance (\%) } \\
\hline & & & SD & MAX & MIN & MEAN \\
\hline S6 & 13.23 & 0.68 & 1.78 & 95.14 & 89.14 & 93.18 \\
\hline S7 & 13.39 & 0.64 & 1.76 & 94.89 & 89.28 & 93.49 \\
\hline S8 & 13.65 & 0.63 & 1.73 & 94.67 & 89.67 & 93.12 \\
\hline S9 & 13.60 & 0.61 & 1.82 & 95.17 & 89.42 & 93.76 \\
\hline S10 & 13.22 & 0.53 & 1.79 & 95.68 & 89.96 & 94.32 \\
\hline
\end{tabular}

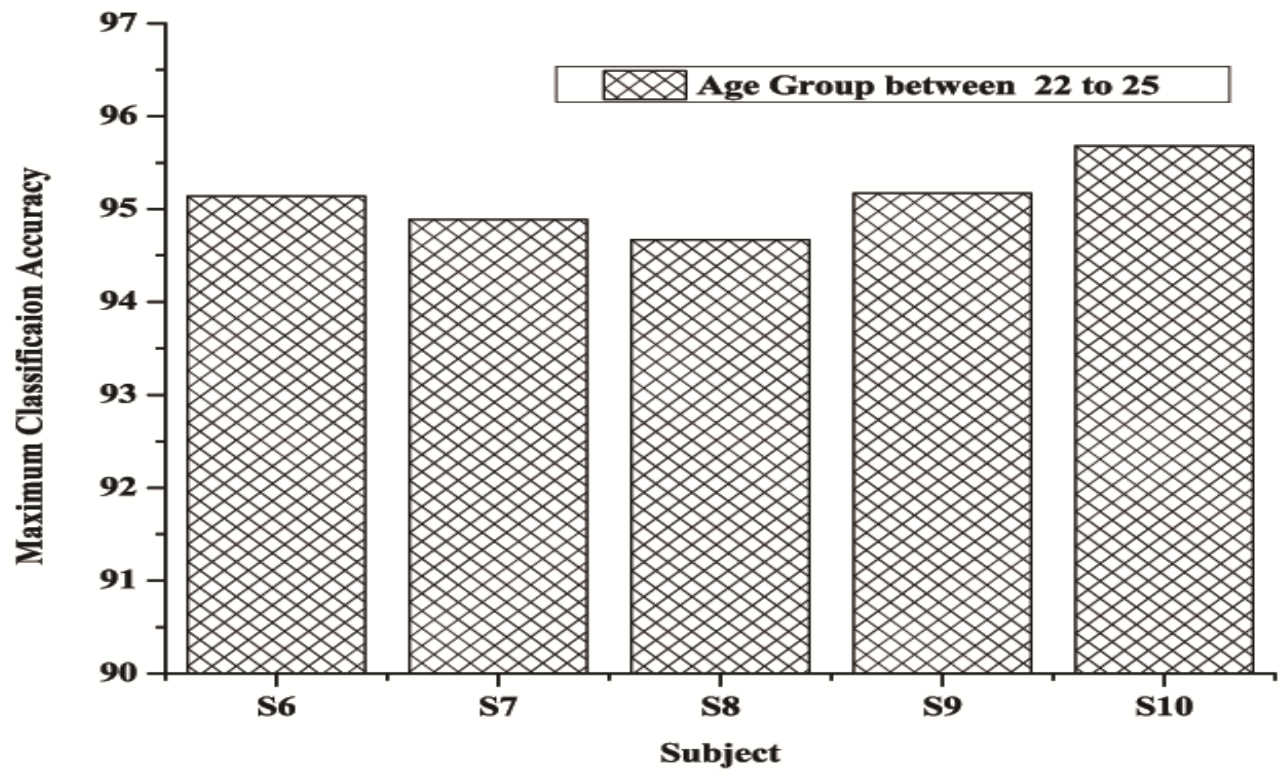

Fig.4. Maximum accuracy of five subjects for the age group between 22 to 25 


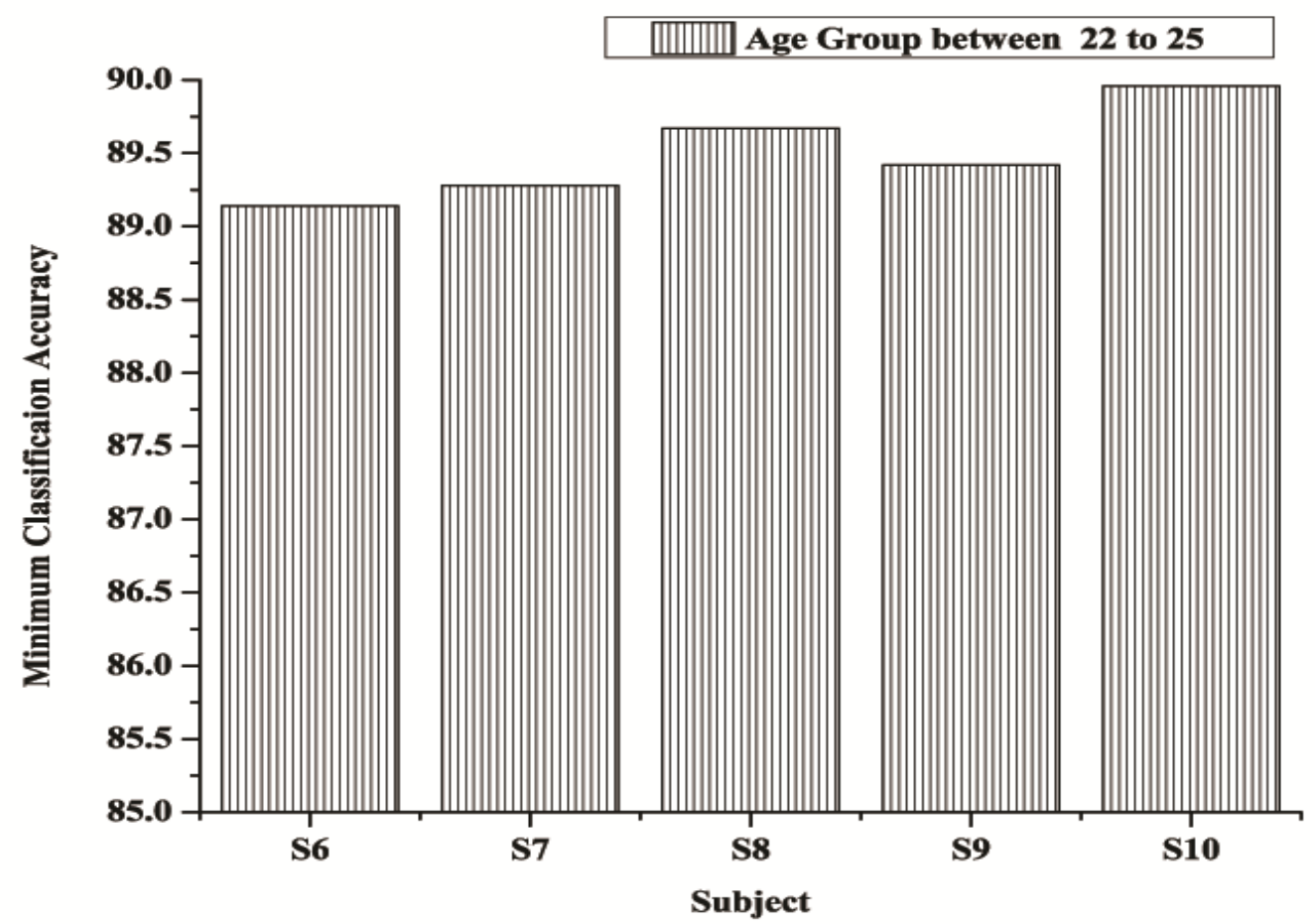

Fig.5. Minimum accuracy of five subjects for the age group between 22 to 25

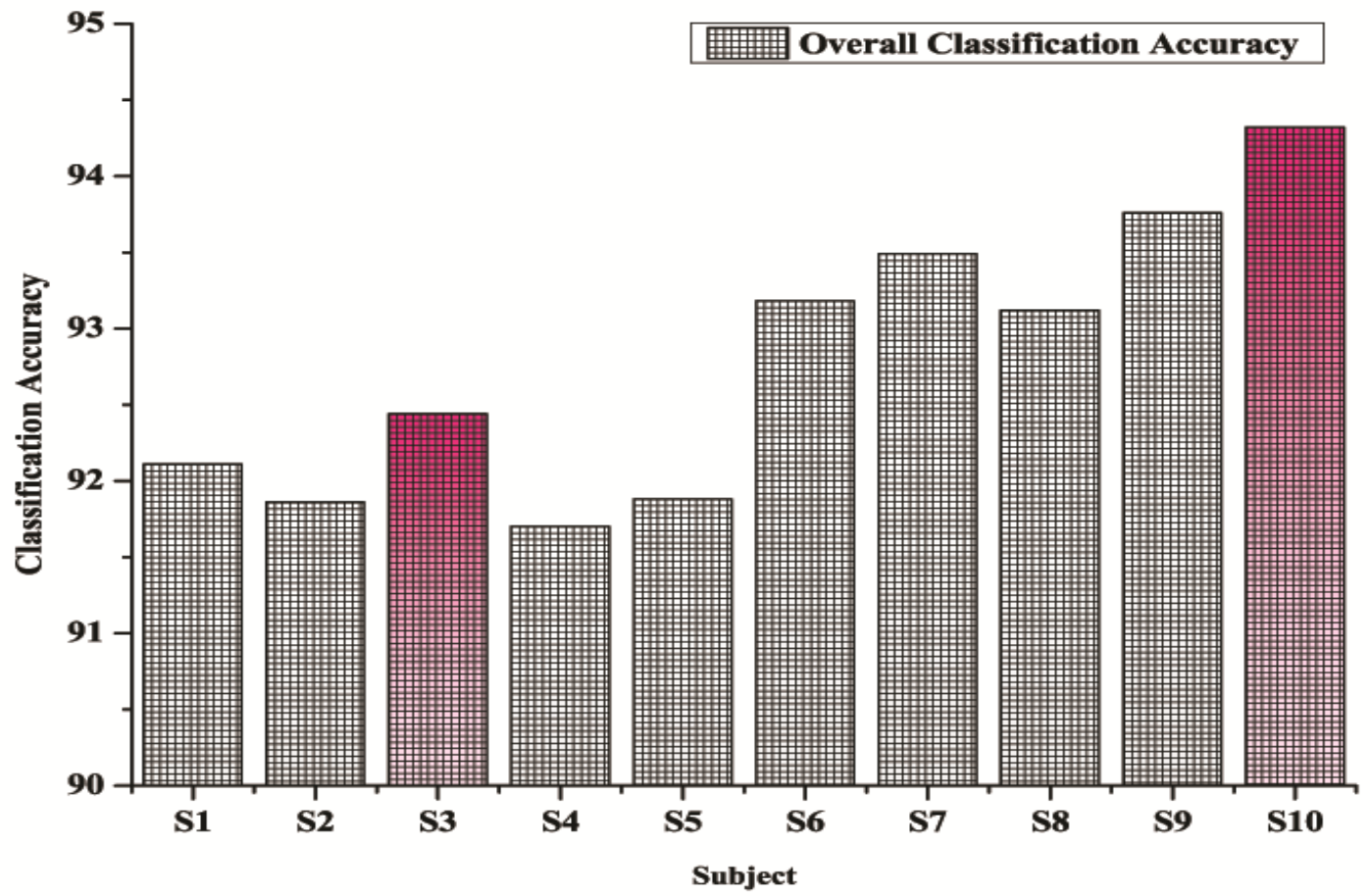

Fig.6. Overall Percentage for two different age groups (Subject S1 to S5 belongs to the age group between 18 to 21 and Subject S6 to S10 belongs to the age group between 22 to 24).

\section{CONCLUSION}

We conducted our experiment with ten subjects with different age groups between 18 to 25 to analyze the performances using EOG signals collected using bio amplifier (Analog Digital Instrument) ADI T26 with five electrodes from five tasks to identify the performances in various age group subjects respectively. From the study we obtained the maximum classification accuracy of $92.44 \%$ for subject S3 and $94.32 \%$ for subject S10 were obtained and also we obtained the minimum classification accuracy of $91.70 \%$ for subject S4 and $93.12 \%$ for subject S8 using Euclidean features with ERNN model. The average classification accuracy of $91.00 \%, 93.57 \%$ were obtained for the age group of 18 to 21 and 22 to 25 .

Published By:

Blue Eyes Intelligence Engineering

\& Sciences Publication 


\section{Classification of Eog Signal using Elman Recurrent Neural Network For Different Age Groups}

Finally from the analyzed result we concluded that subject from the age group 22 to 25 performances were higher than that of age group from 18 to 21 . In the upcoming study we prepared to perform our testing in online with more tasks in real time environment with naive users.

\section{REFERENCES}

1. 1.https://www.aans.org/Patients/Neurosurgical-Conditions -and-Treatments/Spinal-Cord-Injury

2. https://www.britannica.com/science/vertebral-column

3. F.Fang,T.Shinozaki"Electrooculography-based continuous eye writing recognition system for efficient assistive communication systems",PLoS ONE, Vol.13(2), pp.1-20, 2018.

4. R.Scherer, G.Moitzi, I.Daly, G.R.M.Putz, "On the Use of Games for Noninvasive EEG-Based Functional Brain Mapping", IEEE Transactions on Computational Intelligence and AI in Games, Vol.5(2), pp.155-163, 2013.

5. B. Sujatha and G. Ambica, "EEG based brain computer interface for controlling home appliances," International Research Journal of Engineering Technology, vol. 2(9), pp. 580-585, 2015.

6. B.Obermaier, G.R.Muller, G.Pfurtscheller, "Virtual keyboard controlled by spontaneous EEG activity", IEEE Transactions on Neural Systems and Rehabilitation Engineering, Vol.11(4),pp.422 - 426, 2003.

7. A.B.Usakli and S.Gurkan, "Design of a Novel Efficient Human-Computer Interface: An Electrooculagram Based Virtual Keyboard", IEEE Transactions on Instrumentation and Measurement, Vol.59(8),pp.2099 - 2108, 2010.

8. R.Chavarriaga, M.uscumlic, H.Zhang, Z.Khaliliardali, R.Aydarkhanov，S.Saeedi， L.Gheorghe, J.D.R.Millan, "Decoding Neural Correlates of Cognitive States to Enhance Driving Experience", IEEE Transactions on Emerging Topics in Computational Intelligence, Vol.2(4), pp.288-297, 2018.

9. B.Rebsamen, E.Burdet, C.Guan, H.Zhang, C.L.Teo, Q.Zeng, C.Laugier, M.H.Ang, "Controlling a Wheelchair Indoors Using Thought", IEEE Intelligent Systems, Vol.22(2), pp.18-24, 2007.

10. L.C.Sarmiento, P.Lorenzana, C.J.Cortes, W.J.Arcos, J.A.Bacca, A.Tovar, "Brain computer interface $(\mathrm{BCI})$ with EEG signals for automatic vowel recognition based on articulation mode",IEEE Biosignals and Robotics for Better and Safer Living (BRC), pp.1-4, 2014.

11. 11.S.Ramkumar, K.Sathesh Kumar, K.Maheswari, P.Packia Amutha Priya,G.Emayavaramban, J.Macklin Abraham Navamani, "Offline Study For Implementing Human Computer Interface For Elderly Paralyzed Patients Using Electrooculography and Neural Networks", International Journal of Intelligent Enterprise, 2019

12. Q.Huang, Y.Chen, Z.Zhang1, S.He, R.Zhang, J.Liu, Y.Zhang, M.Shao and Y.Li, "An EOG-based wheelchair robotic arm system for assisting patients with severe spinal cord injuries", Journal of Neural Engineering, Vol.16, pp.1-11, 2019.

13. Shao Fang, Ahmed Faeq Hussein, S.Ramkumar, K. S. Dhanalakshm, G.Emayavaramban, "Prospects of Electrooculography in Human-Computer Interface Based Neural Rehabilitation for Neural Repair Patients", IEEE Access, Vol.7, pp. 25506-25515, 2019.

14. Q.Huang, S.He, Q.Wang, Z.Gu, N.Peng, K.Li, Y.Zhang, M.Shao, and Y.Li, "An EOG-Based Human-Machine Interface for Wheelchair Control", IEEE Transactions on Biomedical Engineering",Vol.65(9), pp.2023-2032, 2018.

15. Gu Jialu, S. Ramkumar, G. Emayavaramban, M. Thilagaraj, V Muneeswaran, M. Pallikonda Rajasekaran, Ahmed Faeq Hussein, "Offline Analysis for Designing Electrooculogram Based Human Computer Interface Control for Paralyzed Patients", IEEE Access, Vol.6, pp. 79151-79161, 2018.

16. S.He, Y.Li, "A Single-Channel EOG-Based Speller", IEEE Transactions on Neural Systems and Rehabilitation Engineering, Vol.25(11), pp. 1978 - 1987, 2017.

17. K.R.Lee, W.Chang, S.Kim, C.H.Im, "Real-Time "Eye-Writing" Recognition Using Electrooculogram", IEEE Transactions on Neural Systems and Rehabilitation Engineering, Vo.25(1), pp.37-48, 2017.

18. N.Barbara, T.A.Camilleri, "Interfacing with a speller using EOG glasses",IEEE International Conference on Systems, Man, and Cybernetics (SMC), pp.1-6,2016.

19. A.Rakshit, A.Banerjee, D.N.Tibarewala, "Electro-oculogram based digit recognition to design assitive communication system for speech disabled patients", IEEE-International Conference on Microelectronics, Computing and Communications (MicroCom), 2016.
20. S.Ramkumar, K.Sathesh Kumar G.Emayavaramban," Nine states HCI using Electrooculogram and Neural Networks", International Journal of Engineering and Technology, Vol. 8(6), pp. 3056-3064, 2017.

21. S.Ramkumar, K.Sathesh Kumar G.Emayavaramban," EOG Signal Classification Using Neural Network For Human Computer Interaction" International Journal of Control Theory and Applications, Vol. 9(24), pp. 223-231, 2016.

22. Hema.C.R, Paulraj.M.P \& Ramkumar.S," Classification of Eye Movements Using Electrooculography and Neural Networks", International Journal of Human Computer Interaction, Vol.5 (3), pp.51-63, 2014.

23. https://www.statisticshowto.datasciencecentral.com/ sample- mean/

24. https://www.calculator.net/mean-median-mode-range-

25. calculator.html

26. 25.https://www.statisticshowto.datasciencecentral.com/probability-an d-statistics/statistics-definitions/mean-median-mode/

27. Hema.C.R, Ramkumar.S Paulraj.M.P," Identifying Eye Movements Using Neural Networks for Human Computer Interaction", International Journal of Computer Application, Vol.105 (8), pp.18-26, 2014.

28. S.Ramkumar, K.Sathesh Kumar G.Emayavaramban," A Feasibility Study On Eye Movements Using Electrooculogram Based HCI", IEEE- International Conference on Intelligent Sustainable Systems, pp.384-388, 2017.

29. S.Ramkumar, G.Emayavaramban, K. Sathesh Kumar, J.MacklinAbraham Navamani, K.Maheswari, P.Packia Amutha Priya, "Task Identification System for Elderly Paralyzed Patients Using Electrooculography and Neural Networks", EAI International Conference on Big Data Innovation for Sustainable Cognitive Computing, pp. 151-161, 2020

30. S.Ramkumar,G.Emayavaramban, J.MacklinAbraham Navamani, R.Renuga Devi, A.Prema, B.Booba "Human Computer Interface for Neurodegenerative Patients Using Machine Learning Algorithms", Advances in Computerized Analysis in Clinical and Medical Imaging , 2019.

31. G.Emayavaramban, S.Ramkumar, A.Amudha and K.Sathesh Kumar, "Classification Of Hand Gestures Using FFNN And TDNN Networks", International Journal of Pure and Applied Mathematics, Vol.118(8) Pp. 27-32, 2018.

32. Xin Wan, Kezhong Zhang, S.Ramkumar, J.Deny, G.Emayavaramban, M.Siva Ramkumar, Ahmed Faeq Hussein, "A Review On Electroencephalogram Based Brain Computer Interface For Elderly Disabled",IEEE Access, Vol.7, pp. 36380-36387, 2019.

33. Li Junwei, S.Ramkumar, G.Emayavaramban, D.Franklin vinod, M.Thilagaraj, V.Muneeswaran , M.Pallikonda Rajasekaran, V.Venkatraman, Ahmed Faeq Hussein "Brain Computer Interface For Neurodegenerative Person Using Electroencephalogram, IEEE Access, Vol.7, pp. 2439-2452, 2019.

34. S.Ramkumar,X.Z.Gao, K.Sathesh Kumar, G.Emayavaramban, "Electro-oculogram based rehabilitation using bioengineering techniques for neural disorder person", Journal of Biomedical Imaging and Bioengineering, Vol.2(2), pp.99-101, 2018.

35. S.Ramkumar, K.Sathesh Kumar, T.Dhiliphan Rajkumar, M.Ilayaraja, K.Sankar, "A review-classification of electrooculogram based human computer interfaces", Biomedical Research, 29(6), pp. 1078-1084, 2018.

36. G.Emayavaramban, S.Ramkumar, A.Amudha and K.Sathesh Kumar, "Classification Of Hand Gestures Using FFNN And TDNN Networks", International Journal of Pure and Applied Mathematics, Vol.118(8) Pp. 27-32, 2018.

37. LiKai, S.Ramkumar, J.Thimmiaraja, S.Diwakaran, "Optimized artificial neural network based performance analysis of wheelchair movement for ALS patients", Artificial Intelligence in Medicine, Vol.101, pp.101754, 2019.

38. WenpingTang, AiqunWang, S.Ramkumar, Radeep Krishna RadhakrishnanNair,"Signal identification system for developing Rehabilittive device using deep learning algorithms", Artificial Intelligence in Medicine, Vol.101, pp.101755, 2019. 